\title{
- \\ MOOC Model: Dimensions and Model Design to Develop Learning
}

DOI: 10.15804/tner.2016.43.1.02

\begin{abstract}
Massive Open Online Course (MOOC) is a revolution in education. As learner, teacher presence and teaching method no longer depend upon time and distance, class enrolment also becomes open for more of the populace regardless of educational background. The goal of the research is to design a learning model that is in accordance with dimensions that are compatible with the MOOC rules. Literature review, a questionnaire, and interviews were used to define dimensions based on the MOOC rules. The research resulted in a model that is in accordance with MOOC categories and dimensions based on input from both users and developers.
\end{abstract}

Keywords: MOOC dimension, MOOC Model, learner oriented, e-learning, online courses

\section{Introduction}

Technology development has driven changes in education. E-learning is a learning method that uses technology, such as CD-ROM, internet/intranet, audio, video, application, program, object, website, etc. (Moore, Dickson-Deane \& Galyen, 2011). Online learning or online course is a part of e-learning, a method that allows for flexibility in terms of accessing class activities and contents without the limitations of physical place and time (Cole, 2000).

The online learning method requires devices known as the 'Bring Your Own Device' component, Internet access, and cloud technology. Massive Open Online 
Course (MOOC) is a new online learning method in education that is currently developing. MOOC was founded in 2008 by Siemens et al. In this method, the learner has freedom to choose a course (Scagnoli, 2012), while MOOC provides learning services by using videos, quizzes, blogs, and other online materials (O’Reilly \& Veeramachaneni, 2014). MOOC also incorporates interactions and fosters interconnectivity among learners through online discussion forums, rendering its global and universal nature for learners.

The advantage of the MOOC service for learners is the award of online certification of accomplishment at the end of the course. This certification states that the learner has taken tutorials, problem sets, quizzes, and final examinations for each subject based on provided materials. On the other hand, the advantage of the MOOC service for material providers and instructors is the ability to analyze learning activities through data collection.

With the rapid development and expansion of MOOC and online learning in general, it would be necessary to have a strong basis for comparing MOOC and online learning, especially for dimensional knowledge and development process. This would allow for the determination of the impact that technological development and innovation have in education.

Every development plays its own role in providing operational services and learning contents (Kesima and Altınpulluk, 2014). In this discussion, it is the emphasized 11 questions which are related to time and online learning that is not determined by distance and time. The Learner-Oriented category consists of some dimensions, such as Assessment, Course Offered, General, Human, Instructional, Learning Content, and Time. This category is related to user activities such as observation, submitting, viewing data, taking course attendance, quiz, exams and collaborating about data that have been data standard described by Veeramachaneni, Dernoncourt, Taylor, Pardos, \& O'Reilly (2013). Learner orientation is related to material knowledge and skills (Rosselle, Caron \& Heutte, 2014) as well as the assessment method of learner achievement and development. In the online learning content dimension, everything in accordance with standard can be used repeatedly, after a few adjustments, such as those regarding the difficulty level and material copyrights. Varied sources of learning can also facilitate the learning process. Materials such as videos, online reading, and other digital contents can broaden knowledge (Scagnoli, 2012). Assessment in learning is used as an indicator of the level of skill acquisition. This dimension creation should be tailored to the format and duration of individual sets of material content in order to maximize its quality. Automatic scoring can also be done. The human dimension in learning influences the learning process, taking the role of planning and implementing 
learning development. The human developer requires support from many parties, such as technical assistance, instructional assistance, library assistance, and the actor's feedback/response (in this case, the learner's). To attract users' interest, it is better to pay attention to a general dimension related to naming. Besides that, clear instructions that are easy to understand help users to learn and comprehend the scope of courses offered. The last dimension of learner orientation is time, which is related to the duration of the learning activity.

Community is a part of the Communication category. This dimension is related to the interaction control between learners and teachers through both in-person and online media interactions. For instance, Google+ (Grover, Franz, Schneider, \& Pea, 2013) assists communication through the creation of discussion forums, social media, and linking/blogging, which fosters various communities.

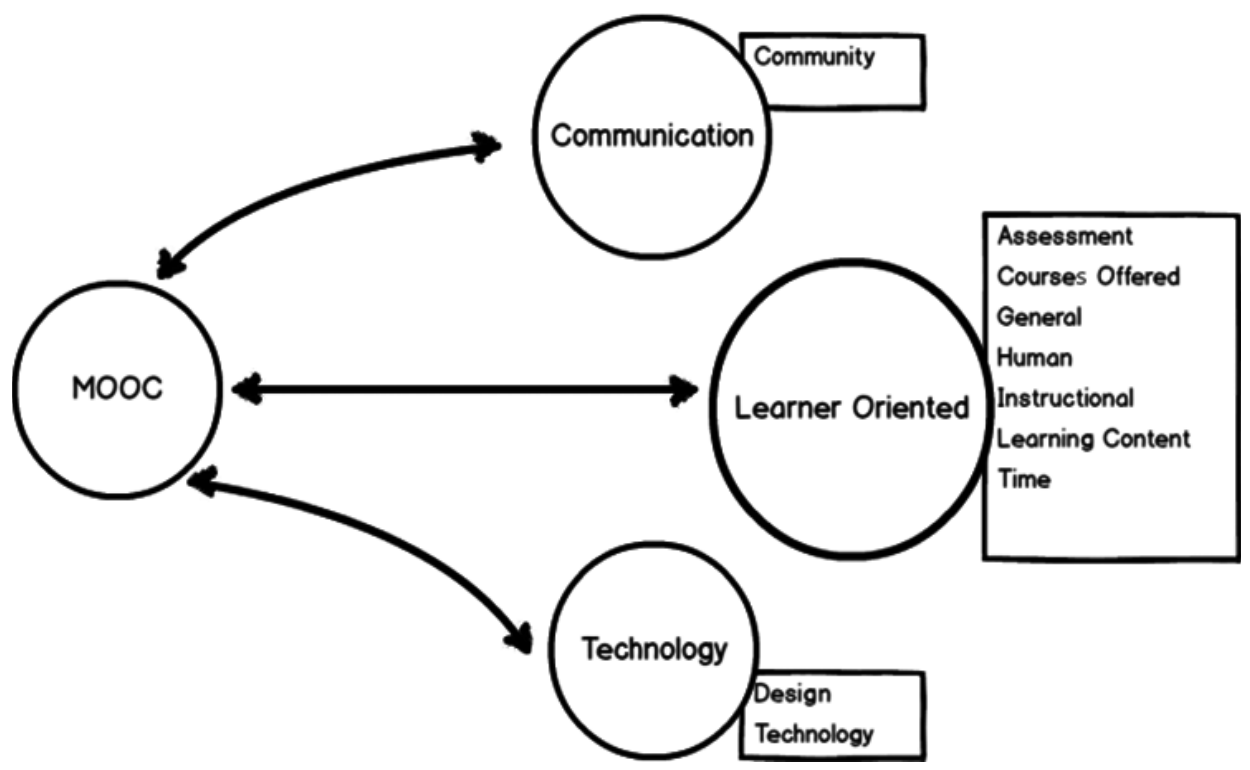

Figure 1. MOOC Concept Model

Technology is an important component in providing online learning. The technology and design dimensions are included in this category, which is related to main technology, support and design. Main technology in learning relates to platform, communication/interaction media, and learning analytics support (Grover, Franz, Schneider \& Pea, 2013). Technology consists of video editors, browser, live 
chat software, office document editor, etc., which are complementary to preparing learning materials. The design of learning consists of adaptive structure and the learning process, while the aim of learning that is in accordance with the standard applied may help the learner to find motivation (Kizilcec, Piech, \& Schneider, 2013).

\section{Method}

The presented study utilized qualitative descriptive methods for the development of a learning model that is in accordance with the MOOC rules. Literature review is used for data collection of previous studies related to online learning dimensions. The concept used in developing a learning model that is in accordance with the MOOC rules defines the relationship between previous studies and the current learning development phenomena. This concept consists of 10 dimensions that are related to one another and divided into 3 categories: Learner Oriented, Communication, and Technology. These 10 dimensions are used in composing 49 questions for the questionnaire, which were used to support the development of learning. The questionnaire and interview were also used for data collection. Questions in this phase were aligned to learning dimensions. Convenience sampling was applied in order to select questionnaire respondents, consisting of lecturers and learners who had had experience with online learning. The interview portion of the data collection was done to garner input from learning developers at universities that have applied online learning. Collected data are analyzed with descriptive statistics by ratio analysis (\%).

In designing the learning model, Unified Model Language (UML) and the model consisting of Use Case, Activity Diagram, Class Diagram, Entity Relationship Diagram, Flow Chart, and User Interface were used.

\section{Result}

\begin{tabular}{ll}
\hline 1. advertisement duration & 2. material duration \\
\hline 3. motivation & 4. accomplishment period \\
\hline 5. time flexibility & 6. learning review \\
\hline 7. time adjustment vs. level of difficulty & 8. impact of quiz duration on result \\
\hline 9. impact of duration on exam result & 10.remedial exam \\
\hline 11. recommendation & \\
\hline
\end{tabular}




\section{Questionaire Analysis}

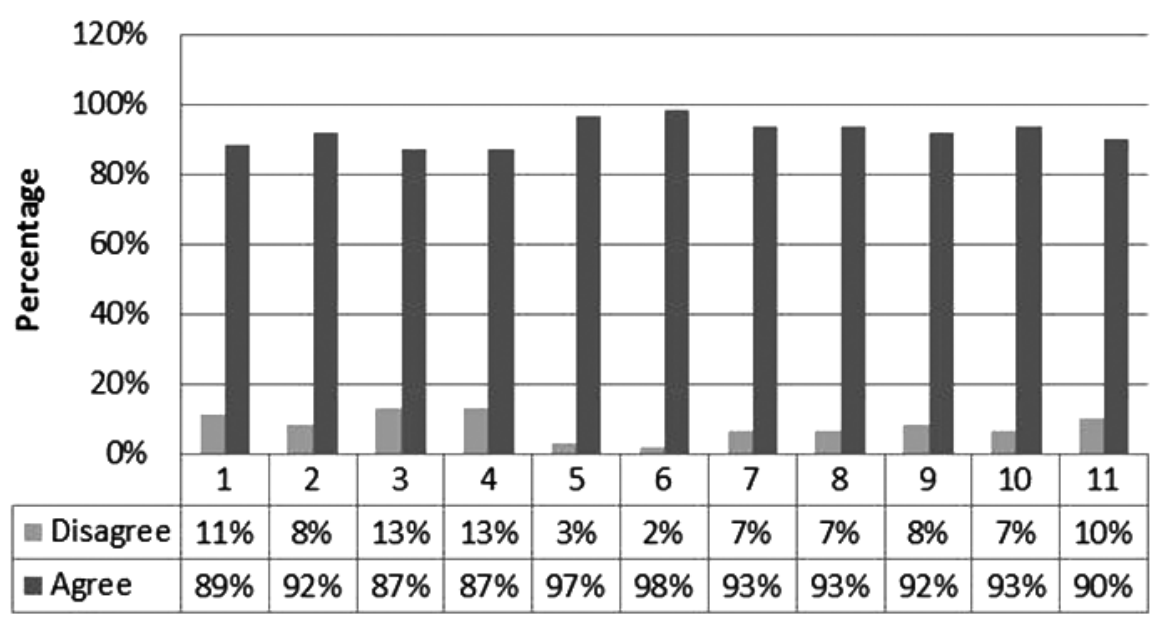

Figure 2. Questionnaires Analytics

Figure 2 shows the results of the study questionnaire covering the relationship between duration and the learning results. Questions in the questionnaire are about what if online learning is supported by using advertisement, duration of video watching, relation between duration and motivation, duration of learning accomplishment, flexibility of learning duration and learning recommendation may cause the learning duration to be well organized. The data will also be used to develop learning design. In Figure 3 there are 40 entities related to the learning material, the learning process, and the users. This design discusses the learning process that is related to the duration dimension and its relationship with potential activities that learners can perform while learning, which are presented in Figures 3 and 4 .

The learning process related to user activities (as described in Figure 3) covered learner, teacher, course, enroll course, course detail, event, source, and share entities. 'User entity' stores data needed to $\log$ in to the learning system, while the detail is stored at entities based on their roles. 'Enroll course' and 'course detail' store data concerning learning. 'Share' stores data concerning sharing activities, 'source' stores data concerning source of material, and 'event' stores data concerning learning activities, material name, duration between starting and accomplishment time (adjusted to the level of difficulty for each material based on $93 \%$ of respondents), 


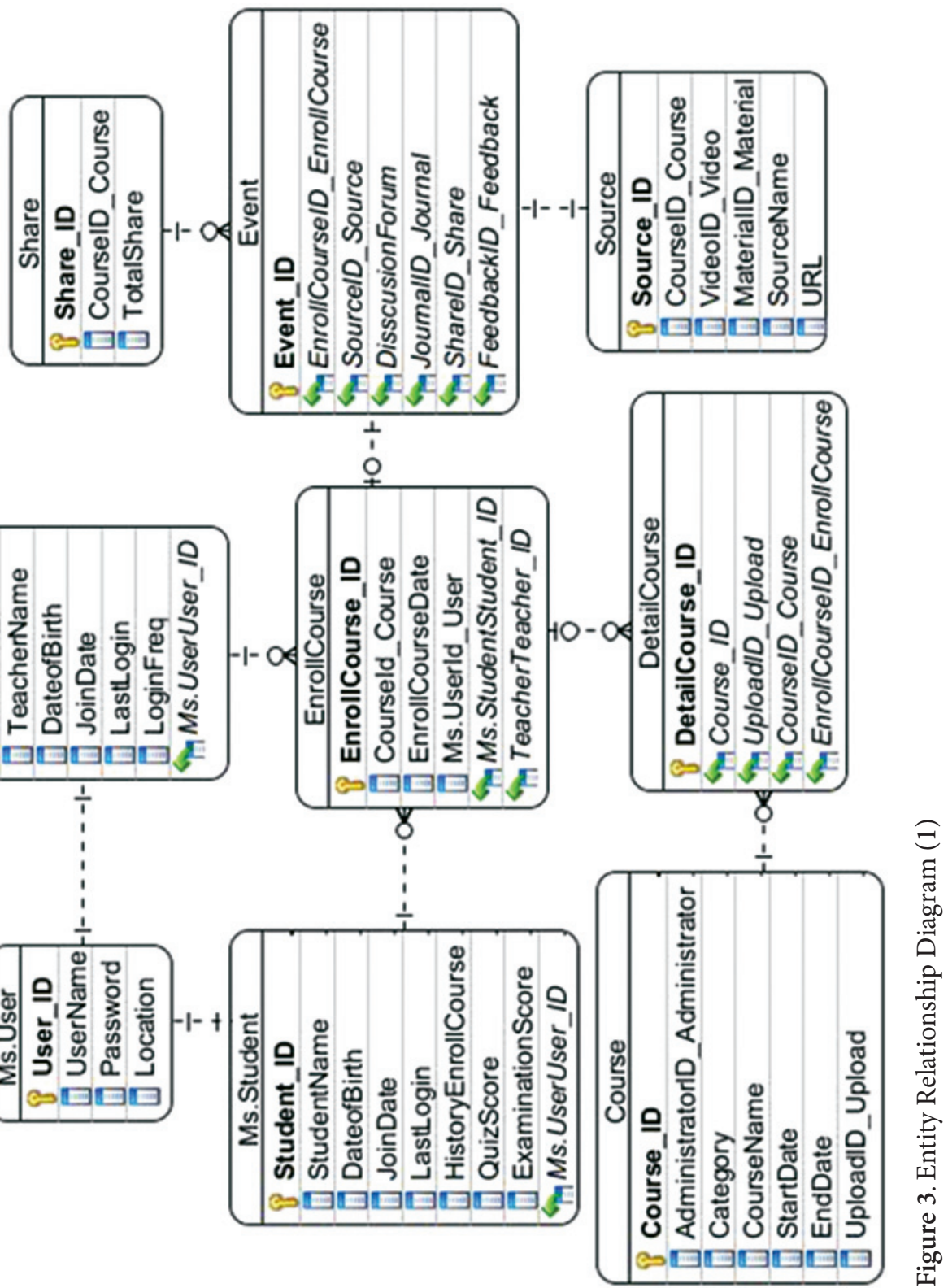




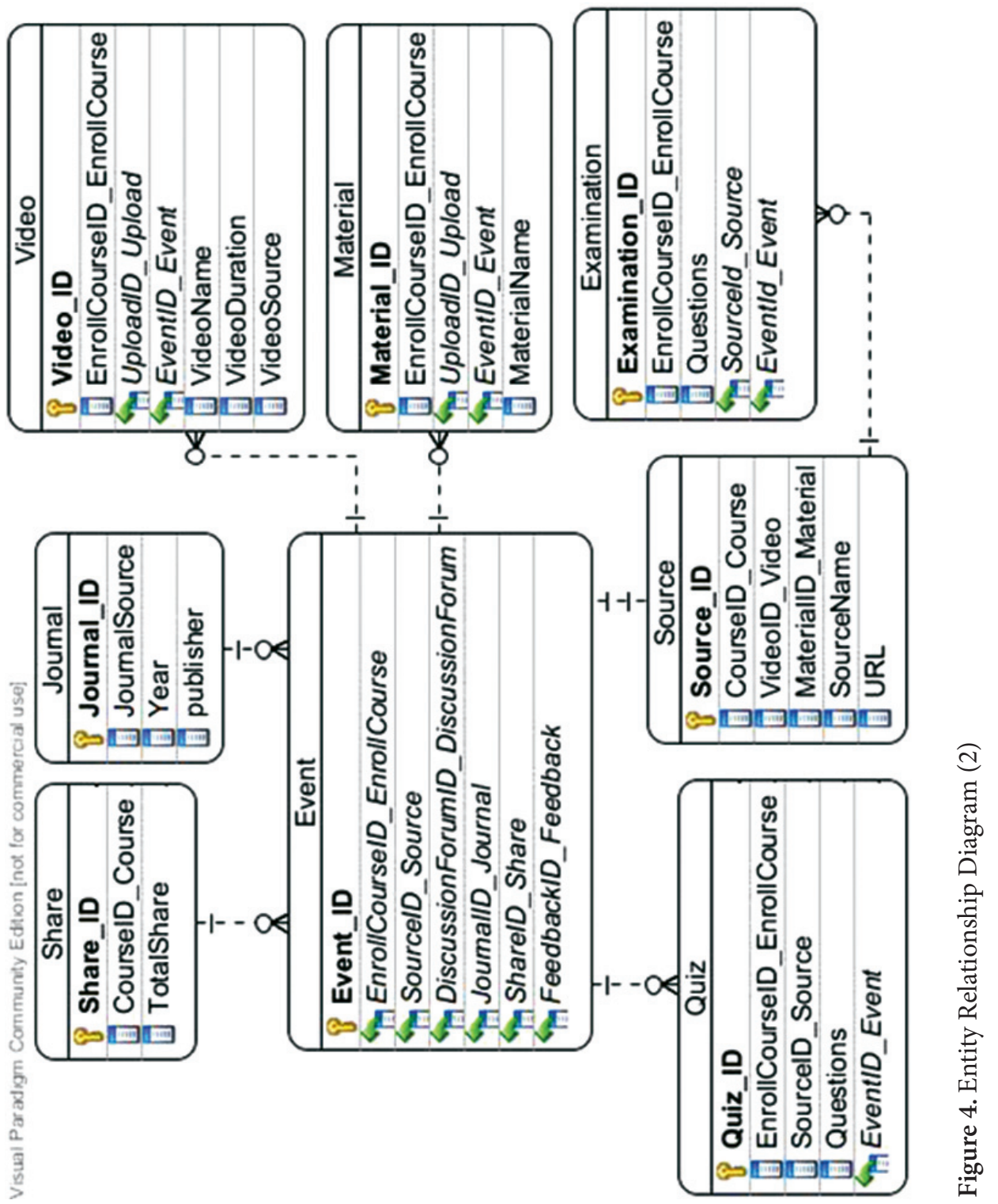


and information about material log. 'Source' stores data concerning material resources that come from many other resources including its material access URL.

Figure 4 shows the relation between event entity and any activities that learners can perform. Design in Figure 4 consists of journal, video, material, quiz, and examination entities. Those entities are related to event entity that covers all activities, duration, and frequency during the enrollment. Based on $93 \%$, it is designed for users to access quizzes during the enrollment period with options to retake the quiz if results do not meet expectations.

Users may perform any actions that are related to journal view, material readings, communication (e.g., discussion), and submission of quiz exercises and examinations. Any actions that users can do are shown in Figure 5.

The use case diagram in Figure 5 shows the actions that users can do with the system, such as enrolling in the course, watching videos, viewing, and downloading materials, viewing, and creating journals, viewing notes, and creating notes, taking quizzes or examinations, reviewing courses, and sharing materials. Before performing these actions, users must log in to the learning system. Registration must be done prior to logging in to the learning system. Then users may choose courses, visit any pages, submit anything related to the course, and update personal data that have been recorded by the system. If a user has enrolled in a course, then he/ she may do any other actions. The details of user interactions during the enrollment are described in Figure 6. User behavior during a quiz is related to several objects that interact with user actions and behavior, which are also illustrated in Figure 6 .

The sequence diagram in Figure 6 describes user action while doing a quiz in a course. After logging in to the system and choosing a material, 'Enroll User' will check the quiz and then the user may do the quiz. Afterwards, the answers will be sent to the system and marked automatically, and then the score will be sentto the user.

After defining user actions, 'User Interface' is designed in order to simplify the description of the information flow between the user and the computer. 'User Interface' is created in order to show information and user action on learning pages.

Figure 7 presents the Initial page of learning, i.e., a page through which a user may register as a new user, log in to the system (after account creation), and read the information that has been provided by the learning service developer. This Initial page is designed to show any information that can be read and understood by anyone who has visited this learning page. The information details include information about the service provider and recommended course materials. The user may also view information about learning through any social media icons that are supplied by the provider. 


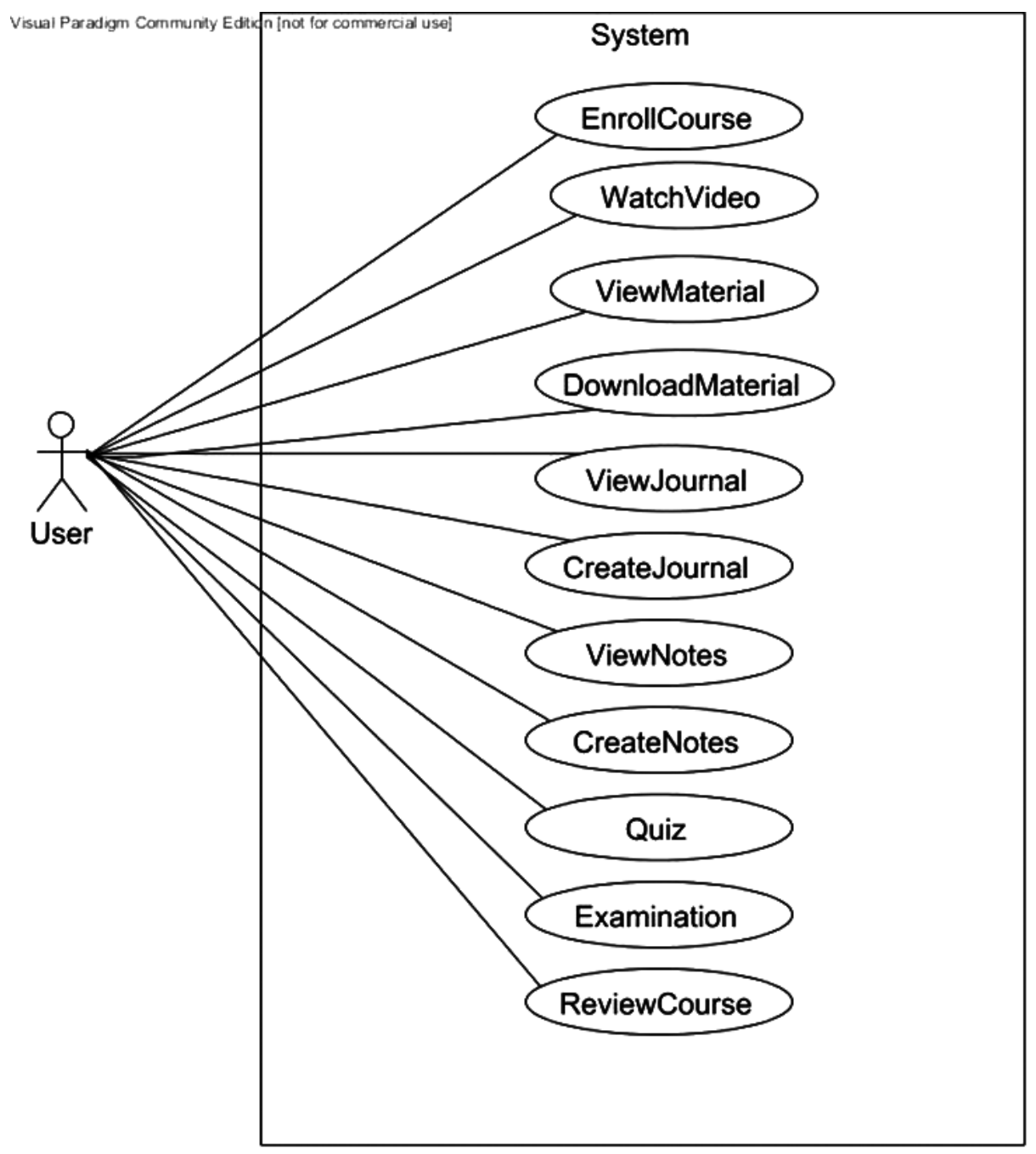

Figure 5. Use Case Diagram 


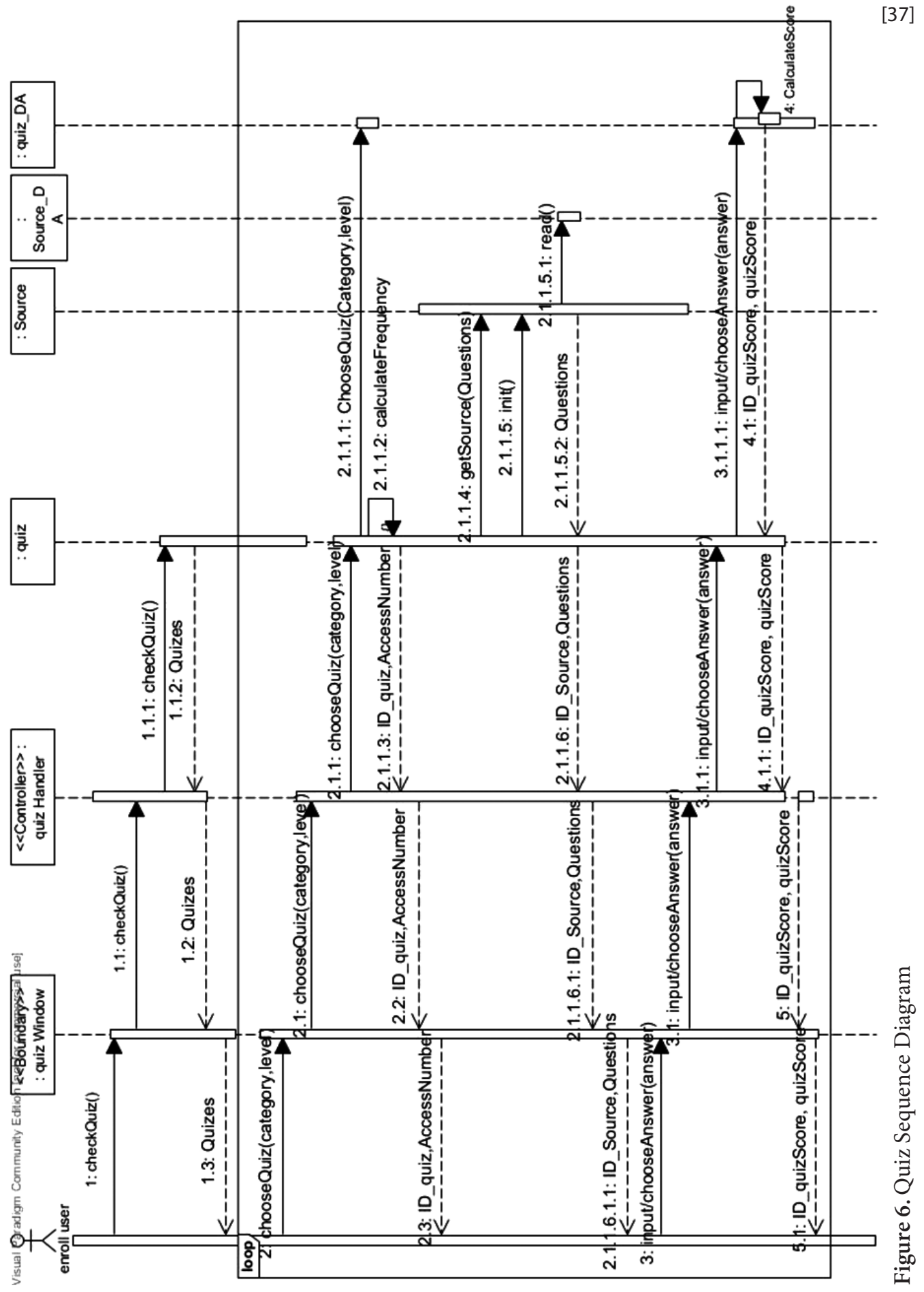




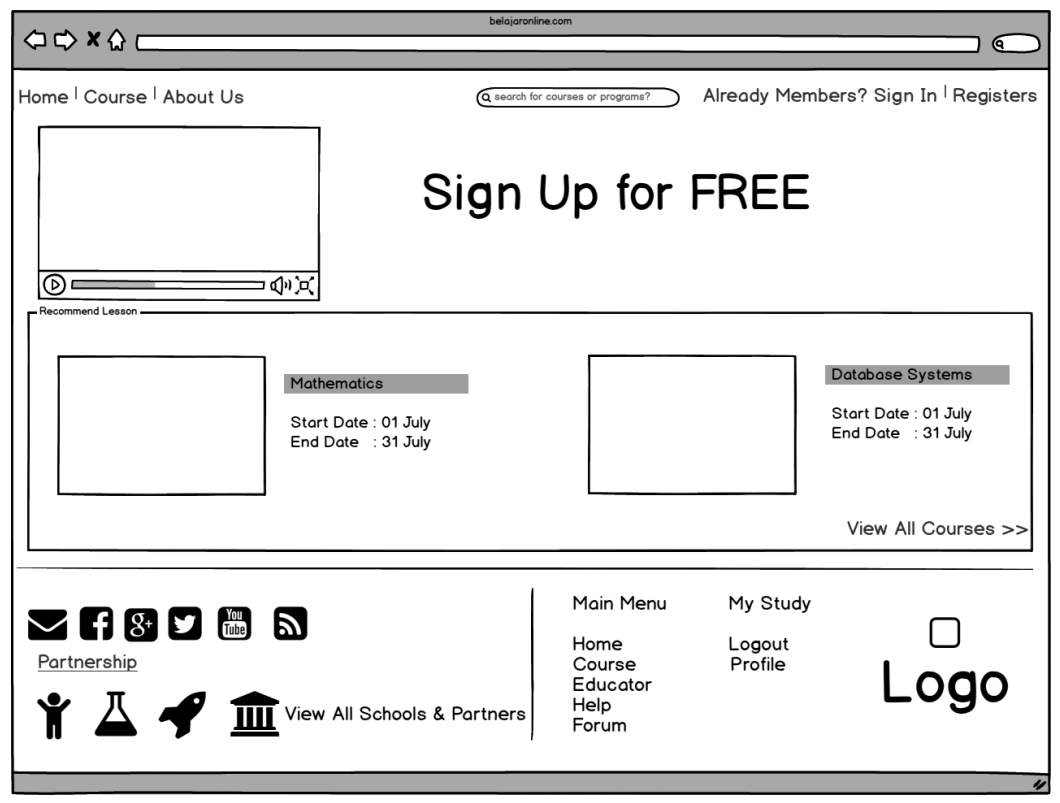

Figure 7. Home User Interface

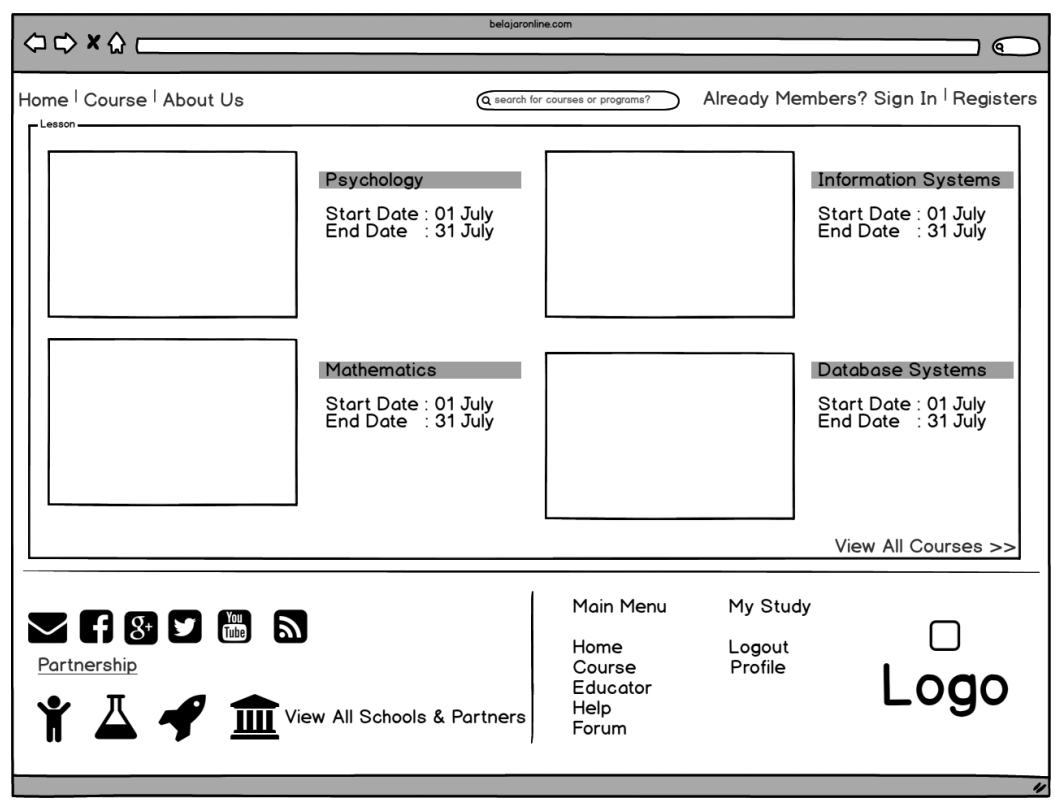

Figure 8. Course User Interface 
The Course page will show the courses offered by the lesson provider. The user may choose a course through the selection of a specific course during a specific time. The user may enroll as long as the registration occurs within the offered time period, during which the user can perform any learning action. The details are described in Figure 9.

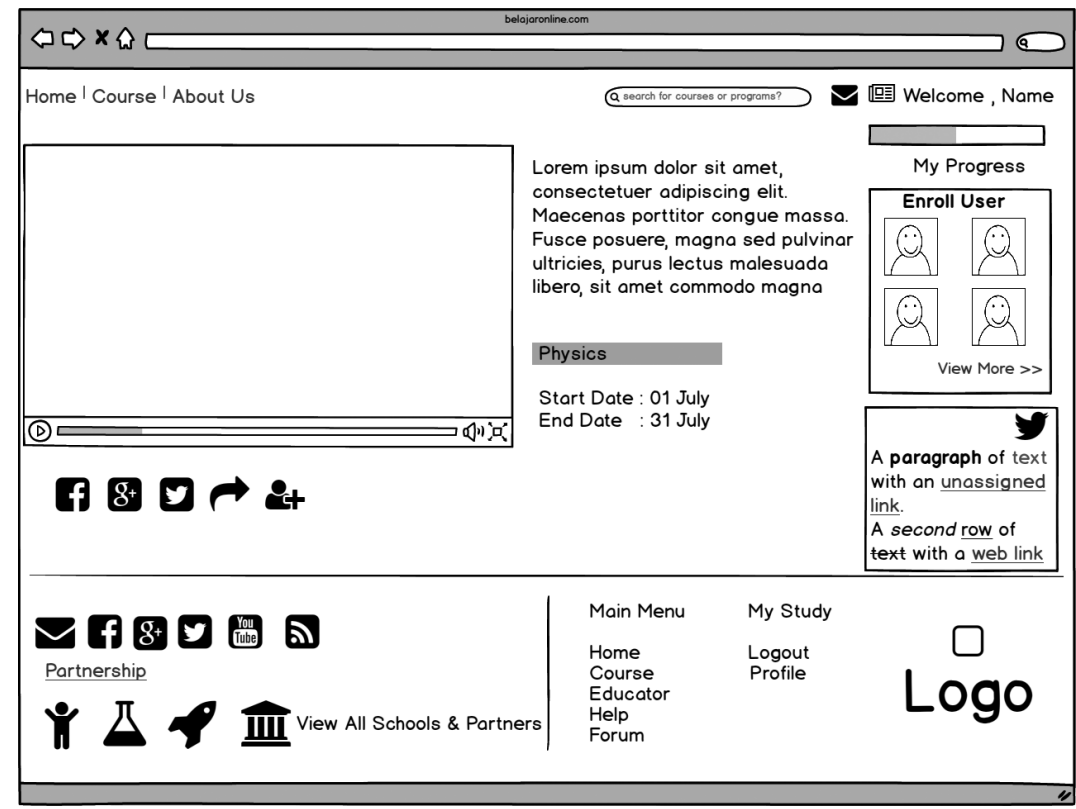

Figure 9. Enroll Course User Interface

On the learning page, users can view their learning progress summarized by a status bar that is placed on the learning page, material video, material description, and list of module. There is also an action tab for the user to support learning, such as class forum, materials, notes, share, and connections. 'Class forum' is used for communication among learners and lecturers to discuss the course. 'Materials' is used for displaying all materials related to learning. 'Notes' is used for taking any notes and viewing previous notes related to learning. 'Connections' is used for viewing any users who have enrolled in the same course. This page is also connected with social media to support communication media among users. The learning and course pages that have been visited and enrolled into by a user are recorded in the user's history log. 


\section{Conclusion}

This research focused on the development of the MOOC model design with 10 dimensions related to one another. Learning model development is described differently, based on the service provider. Integrating input from users and providers enhances the design of the model. Despite its expansive reach, MOOC can be used to target individual users as well. Studying each user is important in order to accumulate ways to personalize and thus improve the quality of the learning experiences. For instance, the 'Time' dimension can be considered as an indicator by which providers can adjust material learning duration and the level of material difficulty of a course; users can also choose the offered learning based on their own interests in order to support motivation and learning activities.

\section{References}

Cole, R.A. (2000). Issues in Web-based Pedagogy: A Critical Primer. Westport. CT: Greenwood Press.

Grover, S., Franz, P., Schneider, E., \& Pea, R. (2013). The MOOC as Distributed Intelligence: Dimensions of Framework \& Evaluation of MOOCs. $10^{\text {th }}$ International Conference on Computer Supported Collaborative Learning, 42-45.

Kesima, M., \& Altınpulluk, H. (2014). A Theoretical Analysis of MOOCs Types from a Perspective of Learning Theories. $5^{\text {th }}$ World Conference on Learning, Teaching and Educational Leadership (WCLTA 2014).

Kizilcec, R.F., Piech, C., \& Schneider, E. (2013). Deconstructing Disengagement: Analyzing Learner Subpopulations in Massive Open Online Courses. In Proceedings of the Third International Conference on Learning Analytics and Knowledge (pp. 170-179). ACM.

Moore, J.L., Dickson-Deane, C., \& Galyen, K. (2011).e-Learning, Online Learning, and Distance Learning Environments: Are They the Same? Internet and Higher Education.

O'Reilly, U.M., \& Veeramachaneni, K. (2014). Technology for Mining the Big Data of MOOCs: Research \& Practice in Assessment, 9(2), 29-37.

Rosselle, M., Caron, P.-A., \& Heutte, J. (2014). A Typology and Dimensions of a Description Framework for MOOCs. EMOOC.

Scagnoli, N.I. (2012). Instructional Design of a MOOC. Thoughts on Instructional Design for MOOCs.

Veeramachaneni, K., Dernoncourt, F., Taylor, C., Pardos, Z., \& O'Reilly, U.M. (2013). MOOCDB: Developing Data Standards for MOOC Data Science. In AIED 2013 Workshops Proceedings (p. 17). 